\title{
ARTIGO
}

\section{Os limites da proporcionalidade na construção civil em tempos de Covid-19}

The limits of proportionality in civil construction in Covid-19 times

\author{
Rui da Silva Vidal, Esp. \\ Bacharel em Direito pela Universidade Federal do Pará - UFPA. \\ Especialista em Direito do Trabalho pela Universidade da Amazônia \\ - UNAMA. Auditor fiscal do trabalho. E-mail: rui.vida31@gmail.com
}

RESUMO: $O$ mundo vive uma das maiores enfermidades epidêmicas da história. $O$ Brasil está entre os países com o maior número de pessoas infectadas e mortas pela COVID-19. Entre as vítimas, muitas são trabalhadoras que se contaminaram no ambiente de trabalho. Dentre os mais afetados, estão os profissionais das áreas da saúde, de frigoríficos e da construção civil, conforme informações dos Ministérios da Saúde e da Economia. Diante desse contexto, a situação de grave e iminente risco no ambiente de trabalho passou a ter outro olhar. Na construção civil, os riscos de queda e de choque elétrico somam-se ao risco de adoecimento pelo coronavírus. Nessa nova perspectiva, a proporcionalidade passa a ter um papel de suma importância na ponderação dos interesses fundamentais da coletividade. A NR-3, aplicável às situações de grave e iminente risco, deve ser modulada à realidade do risco biológico decorrente da COVID19. Assim, fatos que eram simples irregularidades nos canteiros de obra, hoje, são considerados excesso de risco à saúde dos trabalhadores. Tais eventos autorizam, por si sós, a paralisação temporária da obra. Diante desse novo quadro, a auditoria fiscal do trabalho deve adotar o embargo quando o empregador não construir as áreas de vivência, tais com: instalações sanitárias, vestiário, local para refeição e alojamento, ou quando forem inadequadas para uso dos trabalhadores, em face da pandemia da COVID-19. A medida restritiva aparece como ato adequado para corrigir distorções no ambiente laboral e prevenir os trabalhadores contra doenças ocupacionais.

Palavras-chave: coronavírus, dignidade, direitos fundamentais, grave e iminente risco, saúde e segurança no trabalho.

Laborare. Ano IV, Número 6, Jan-Jun/2021, pp. 172-193. ISSN 2595-847X. https://revistalaborare.org/ DOI: https://doi.org/10.33637/2595-847x.2021-71 


\begin{abstract}
The world is experiencing one of the greatest epidemic diseases in history. Brazil is among the countries with the highest number of people infected and killed by COVID-19. Among the victims, many are workers who have become contaminated in the workplace. Among the most affected are the professionals in the areas of health, slaughterhouses and civil construction, according to information from the Ministries of Health and Economy. In this context, the situation of severe and imminent risk in the work environment started to take another look. In construction, the risks of falling and electric shock are added to the risk of becoming ill with the coronavirus. In this new perspective, the proportionality starts to play an extremely important role in balancing the fundamental interests of the community. The NR-3, applicable in situations of serious and imminent risk, must be modulated to the reality of biological risk arose from COVID-19. Thus, facts that were simple irregularities in the building sites, today, are considered to be an excessive risk to workers' health. Such events alone authorize the temporary interruption of the work. In view of this new situation, the labor tax audit must adopt the embargo when the employer does not build living areas, such as: sanitary facilities, dressing room, place for meals and accommodation, or when they are unsuitable for use by workers, in COVID-19 pandemic. The restrictive measure appears as an appropriate act to correct distortions in the work environment and prevent workers from occupational diseases.
\end{abstract}

Keywords: coronavirus, fundamental rights, severe and imminent risk, health and safety at work.

\title{
1. INTRODUÇÃO
}

O direito tem um papel de suma importância em tempos de COVID-19 ${ }^{1}$. Novos regramentos são editados para atender as questões emergenciais. Todavia, tem sido tarefa complexa conciliar o sistema normativo regular com o microssistema temporário criado para reger a vida das pessoas durante a pandemia da COVID-19. Para a correta interpretação do direito na atualidade, é preciso que se estabeleça uma comunicação entre as diversas fontes. Nesse sentido, o pós-positivismo abriu novas possibilidades para que o intérprete encontre o sentido da norma que melhor se coadune com as regras e princípios constitucionais (VIDAL; SOUSA, 2018).

A auditoria fiscal do trabalho deve adotar esse tipo de interpretação, conciliando, à luz da Constituição Federal, as fontes jurídicas, aplicando o princípio da

1 A COVID-19 é uma doença infecciosa causada por um coronavírus recém-descoberto (SARS-COV-2).

Laborare. Ano IV, Número 6, Jan-Jun/2021, pp. 172-193. ISSN 2595-847X. https://revistalaborare.org/ DOI: https://doi.org/10.33637/2595-847x.2021-71 
proporcionalidade na construção civil em tempos de COVID-19, por meio do embargo. Nessa concepção, a medida restritiva vai além do aspecto normativo, pois deve prevalecer a dignidade do trabalhador sobre o aspecto econômico da relação de trabalho, no processo de ponderação dos interesses em jogo.

A Norma Regulamentadora n. $^{\circ} 3$ (NR-3) é o instrumento normativo que cuida do grave e iminente risco no ambiente de trabalho. Seu texto estabelece critérios objetivos para identificar tal situação, disciplinando as consequências que podem advir da sua aplicação. $\mathrm{O}$ embargo surge, nessa situação, como ato originário do poder de polícia da administração pública, sem o caráter punitivo, fundamentado na situação de grave e iminente risco. Entre os seus objetivos, destacam-se os seguintes: limitar o exercício da autonomia privada; prevenir doenças ocupacionais; preservar o direito fundamental à saúde; resgatar a dignidade dos trabalhadores da construção civil; garantir o meio ambiente do trabalho sadio e equilibrado.

Nesse contexto, observa-se uma relação entre o agente patogênico SARS-COV-2, responsável pela COVID-19, e a inexistência de áreas adequadas de vivência nos canteiros de obra, tais como: instalações sanitárias, local para refeições, vestiário e alojamento. Essa falta de instalações adequadas expõe os trabalhadores da construção civil ao risco de adoecimento, com a alta probabilidade de serem acometidos de doença ocupacional, podendo provocar a morte. Sobre tal problemática, indaga-se: Em face da pandemia da COVID-19, a ausência das áreas de vivência no canteiro de obra ou quando forem inadequadas para uso dos trabalhadores, por si só, deve justificar a adoção do embargo como medida cautelar instaurada pelo auditor fiscal do trabalho? $\mathrm{O}$ presente artigo procura responder à questão afirmativamente, mediante a aplicação do princípio da proporcionalidade, que será usado como fio condutor para tornar justa a relação entre construtor, trabalho e trabalhador, efetivando a proteção normativa e a proteção além da norma.

\section{AUDITORIA FISCAL DO TRABALHO E O EXERCÍCIO DO PODER DE POLÍCIA POR MEIO DO EMBARGO}

Compete à inspeção do trabalho verificar o cumprimento das disposições legais e regulamentares. Nessa análise, os auditores fiscais do trabalho devem dar atenção especial àquelas normas relacionadas à segurança e à saúde no trabalho, conforme o Regulamento da Inspeção do Trabalho (Decreto n. ${ }^{\circ}$ 4.552, de 27 de dezembro de 2002). Em novo diploma legal, a inspeção foi definida como serviço público essencial, indispensável à preservação da saúde e da segurança nos ambientes de

Laborare. Ano IV, Número 6, Jan-Jun/2021, pp. 172-193. ISSN 2595-847X. https://revistalaborare.org/ DOI: https://doi.org/10.33637/2595-847x.2021-71 
trabalho, notadamente durante a pandemia da COVID-19 (Decreto n. ${ }^{\circ}$ 10.282, de 20/03/2020).

Dentre as diversas formas de garantir a saúde e a segurança no ambiente do trabalho, destaca-se o embargo como medida de urgência. O auditor fiscal do trabalho deve adotar esse instrumento, ao constatar alguma situação que caracterize grave e iminente risco à saúde do trabalhador. Ante essa evidência, determina a paralisação parcial ou total da obra, nos termos da NR-3. Ao proceder ao embargo, restringe os direitos fundamentais à livre iniciativa e à autonomia privada. Em contrapartida, prioriza os direitos fundamentais à saúde do trabalhador e ao ambiente do trabalho sadio e equilibrado, com base no exercício da ponderação de interesses.

Os limites aos direitos fundamentais estão previstos na própria Carta Magna e nas normas infraconstitucionais, podendo ser executados por decisões judiciais e por atos administrativos. Dessa forma, a administração pública pode restringir direitos fundamentais, desde que exista fundamento constitucional e o faça em obediência ao princípio da proporcionalidade. Nessa linha, Barroso (2019, p. 509) assinala: "Um mecanismo típico de interferência da administração pública nos direitos fundamentais é o exercício do poder de polícia, pelo qual interesses individuais são conformados aos interesses da coletividade".

No caso em debate, o fundamento constitucional do poder de polícia exercido pela inspeção do trabalho está insculpido no inciso XXII do art. $7^{\circ}$ da Constituição Federal. Segundo dispõe, é direito dos trabalhadores a "redução dos riscos inerentes ao trabalho, por meio de normas de saúde, higiene e segurança". A base infraconstitucional, por sua vez, está prevista no capítulo V, título II, da Consolidação das Leis do Trabalho (CLT), que autoriza a administração pública a expedir normas e instruções sobre segurança e medicina do trabalho. Nessas hipóteses, os direitos fundamentais positivos, geradores de obrigações afirmativas, são garantidos por meio de proteção normativa: constituição, leis e regulamentos. Ao tratar da natureza das normas regulamentadoras sobre saúde e segurança no trabalho, estabelecidas na Constituição Federal e na CLT, Delgado (2014, p. 150) esclarece:

Lei em sentido material se constitui em toda regra de direito geral, abstrata, impessoal, obrigatória, oriunda de autoridade competente e expressa em fórmula escrita. Já a lei em sentido formal é regra jurídica geral, abstrata, impessoal, obrigatória, emanada do Poder Legislativo, sancionada e promulgada pelo chefe do Executivo.

Laborare. Ano IV, Número 6, Jan-Jun/2021, pp. 172-193. ISSN 2595-847X. https://revistalaborare.org/ DOI: https://doi.org/10.33637/2595-847x.2021-71 
Como se observa, as normas regulamentadoras nas áreas da saúde, higiene e segurança no trabalho possuem generalidade, abstração e impessoalidade. Essas características decorrem do fato de tais normas serem oriundas de autoridade competente e expressas de forma escrita, com assento na Constituição da República. Nesse sentido, a NR-3 estabelece os pressupostos para a caracterização do grave e iminente risco, bem como os requisitos técnicos objetivos de embargo e interdição. Significa dizer que a citada norma encontra seu fundamento no princípio da igualdade.

\section{COLISÃO ENTRE DIREITOS FUNDAMENTAIS: APLICAÇÃO DA TÉCNICA DA PONDERAÇÃO}

É importante trazer à baila as diferenças entre princípios e regras como normas jurídicas. Essa distinção entre as espécies normativas é fundamental para melhor compreensão da decisão do auditor fiscal do trabalho ao restringir o direito fundamental à livre iniciativa. Com essa medida, busca assegurar os direitos fundamentais ao ambiente do trabalho saudável, à saúde do trabalhador e à saúde da coletividade.

Atribui-se a Ronald Dworkin, com sua obra "Levando os direitos a sério", amplamente difundida no Brasil nos anos de 1990, o pioneirismo na distinção entre princípios e regras. Barroso (2018, p. 243-246) apresenta três critérios para melhor compreensão dessa distinção: o conteúdo, a estrutura normativa e o modo de aplicação. Em seguida, esclarece:

No tocante ao conteúdo, princípio identifica as normas que expressam decisões políticas fundamentais, valores a serem observados em razão da sua dimensão ética ou fins públicos a serem realizados. As regras jurídicas, ao revés, são comandos objetivos, prescrições que expressam diretamente um preceito, uma proibição ou uma permissão. Com relação à estrutura normativa, princípios normalmente apontam para estados ideais a serem buscados, sem que o relato da norma descreva de maneira objetiva a conduta a ser seguida. Há muitas formas de respeitar ou fomentar o respeito à dignidade humana, de exercer com razoabilidade o poder discricionário ou de promover o direito à saúde. Aliás, é nota de singularidade dos princípios a indeterminação de sentido a partir de certo ponto, assim como a existência de diferentes meios para sua realização. Tal abertura faz com que os princípios funcionem como uma instância reflexiva, permitindo que os diferentes argumentos e pontos de vista existentes na sociedade, acerca dos valores básicos subjacentes à constituição, ingressem na ordem jurídica e sejam processados segundo a

Laborare. Ano IV, Número 6, Jan-Jun/2021, pp. 172-193. ISSN 2595-847X. https://revistalaborare.org/ DOI: https://doi.org/10.33637/2595-847x.2021-71 
lógica do direito. Já com as regras se passa de modo diferente: são elas normas descritivas de comportamentos, havendo menor grau de ingerência do intérprete na atribuição de sentido aos seus termos e na identificação de suas hipóteses de aplicação. É, todavia, no modo de aplicação que reside a principal distinção entre regra e princípio. A regra se aplica na modalidade tudo-ou-nada: ocorrendo o fato descrito no seu relato, ela deverá incidir, produzindo o efeito previsto. Por isso se diz que as regras são mandados ou comandos definitivos. Já os princípios indicam uma direção, um valor, um fim. Ocorre que, em uma ordem jurídica pluralista, a constituição abriga princípios que apontam em direções diversas, gerando tensões e eventuais colisões entre eles. Como todos os princípios têm o mesmo valor jurídico, a prevalência de um sobre o outro não pode ser determinada em abstrato; somente à luz dos elementos do caso concreto será possível atribuir maior importância a um do que a outro. Ao contrário das regras, princípios são aplicados de acordo com a dimensão de peso que assumem na situação específica. Caberá ao intérprete proceder à ponderação ).dos princípios e fatos relevantes. (BARROSO, 2018).

Vale destacar que a estrutura normativa e o modo de aplicação dos direitos fundamentais se equiparam aos princípios. O presente trabalho evidencia colisões entre os princípios fundamentais da livre iniciativa, de um lado, e o valor social do trabalho e a preservação do ambiente do trabalho, do outro. Analisa, também, o choque entre o princípio da livre iniciativa e os direitos fundamentais à saúde e à dignidade do trabalhador.

As colisões de normas constitucionais são decorrentes do Estado pós-positivista. Os critérios e técnicas que existiam para solucionar conflitos entre regras não são mais adequados para harmonizarem as colisões entre direitos fundamentais. Para a jurisprudência e a doutrina dominantes no Brasil, não existe hierarquia, no aspecto abstrato, entre tais direitos. Dessa forma, a preponderância de um sobre o outro deve ser determinada à luz do caso concreto. Fica, então, evidente que os valores e princípios albergados pela Lei Maior não são absolutos. Concretamente, a precedência de um direito fundamental sobre o outro é determinada pela técnica da ponderação, que tem como linha condutora o princípio da proporcionalidade. Além de ser acolhido por grande parte da doutrina, o Supremo Tribunal Federal tem adotado esse critério em algumas decisões. A esse respeito, acrescenta Barroso (2019, p. 319):

A ponderação consiste em uma técnica de decisão jurídica, aplicável aos casos difíceis, notadamente na colisão de princípios e direitos fundamentais, em relação às quais a subsunção se mostrou insuficiente.

Laborare. Ano IV, Número 6, Jan-Jun/2021, pp. 172-193. ISSN 2595-847X. https://revistalaborare.org/ DOI: https://doi.org/10.33637/2595-847x.2021-71 
Esta técnica de aplicação no direito se desenvolve por via de um raciocínio silogístico, no qual a premissa maior - a norma, incide sobre a premissa menor - os fatos -, produzindo um resultado, fruto da aplicação da norma ao caso concreto. A sua insuficiência se deve ao fato de existirem normas de mesma hierarquia, indicando soluções diferenciadas. Como consequência, a interpretação constitucional desenvolveu a técnica da ponderação, capaz de produzir uma solução dotada de racionalidade e de controlabilidade diante de normas que entrem em rota de colisão.

\section{PROPORCIONALIDADE E RAZOABILIDADE}

O princípio da razoabilidade surgiu nos Estados Unidos, em decorrência do princípio do devido processo legal. Já o princípio da proporcionalidade teve sua origem na Alemanha, no âmbito do direito administrativo. Discorrendo sobre essa gênese, anota Barroso (2019, p. 249-250):

O princípio da razoabilidade teve início com a Carta Magna de 1215 (João sem-Terra). Percorreu duas fases até o amparo constitucional, com as emendas 4 e 14 da Constituição Norte-Americana. A primeira foi de caráter puramente processual, de início voltado para o processo penal (direito de ação, ampla defesa, etc.). A outra fase foi de caráter substantivo, em que o Judiciário passou a exercer o controle de mérito sobre a discricionariedade do legislador, na defesa dos direitos de liberdade e de propriedade. Verificava a compatibilidade entre os meios e os fins visados pelo legislador. É nesse sentido que a razoabilidade surge nos Estados Unidos como um princípio constitucional de controle de constitucionalidade. $\mathrm{O}$ princípio da proporcionalidade, por seu turno, teve início na Alemanha, no âmbito do direito administrativo, como limitação à discricionariedade administrativa, já que o poder do legislador era juridicamente ilimitado, uma vez que a soberania popular era exercida pela supremacia do parlamento. Com a lei fundamental de 1949, a ideia de proporcionalidade passou a ter fundamento constitucional, com a conversão do princípio da reserva legal em princípio da reserva da lei proporcional. Regia uma relação racional entre os meios e os fins, tanto na esfera legislativa como administrativa, sendo que impõe maiores restrições ao administrador.

O Supremo Tribunal Federal, em diversas decisões, vem firmando o entendimento de que proporcionalidade e razoabilidade formam um único princípio (RE 200844, Ação Direta de Inconstitucionalidade (ADI) 1753, Habeas Corpus (HC) 76060 e RE 251.445-GO). No entanto, há controvérsias na doutrina sobre a equivalência dos

Laborare. Ano IV, Número 6, Jan-Jun/2021, pp. 172-193. ISSN 2595-847X. https://revistalaborare.org/ DOI: https://doi.org/10.33637/2595-847x.2021-71 
referidos princípios. Para uma corrente, a razoabilidade possui contornos mais difusos e fluidos, enquanto a proporcionalidade costuma ser associada ao juízo tridimensional (adequação, necessidade e proporcionalidade no sentido estrito). Todavia, há consenso no sentido de que ambos estão vinculados à ideia de moderação, justiça adequada, racionalidade e rejeição aos atos arbitrários. Dessa forma, servem de parâmetros para a aferição da legitimidade constitucional das leis e dos atos administrativos, bem como das decisões judiciais. A esse respeito, escreve Pereira (2018, p. 359):

A proporcionalidade, como critério de aferição da constitucionalidade das medidas restritivas de direito, traduz uma estrutura de pensamento consistente em avaliar a correlação entre os fins visados e os meios empregados nos atos do poder público. O princípio da proporcionalidade serve para analisar a relação entre interesses e bens que estejam em confronto, podendo ser qualificado, portanto, como um critério estrutural para a determinação do conteúdo constitucionalmente vinculante dos direitos fundamentais.

Também existe divergência quanto à natureza jurídica da proporcionalidade como princípio. Os doutrinadores que contestam esse conceito argumentam que não se trata de um comando normativo que possa ser aplicado em diversos graus. Portanto, não se caracteriza como comando de otimização. Para Alexy (1997, p. 86), a expressão mais adequada é a máxima da proporcionalidade, esclarecendo:

Adequação, necessidade e proporcionalidade em sentido estrito devem ser entendidas como regras e não como subprincípios. O ponto decisivo para a distinção entre regras e princípios é que os princípios são normas que ordenam que algo seja realizado na maior medida possível, dentro das possibilidades jurídicas e reais existentes. Portanto, os princípios são mandados de otimização, que estão caracterizados pelo fato de que podem ser cumpridos em diferentes graus e que a medida devida do seu cumprimento depende não apenas das possibilidades reais, senão também das possibilidades jurídicas. O âmbito de possibilidades jurídicas é determinado pelos princípios e regras opostos.

No entendimento de Ávila (2001), "a proporcionalidade não pode ser qualificada como regra nem como princípio, mas como um postulado normativo aplicativo. Os postulados são metanormas ou normas de segundo grau, as quais operam como estrutura para aplicação de outras normas". De modo geral, as constituições não se referem, expressamente, ao princípio da proporcionalidade. Na Alemanha, a Corte Constitucional extrai o referido princípio da cláusula do Estado de Direito. Nos

Laborare. Ano IV, Número 6, Jan-Jun/2021, pp. 172-193. ISSN 2595-847X. https://revistalaborare.org/ DOI: https://doi.org/10.33637/2595-847x.2021-71 
Estados Unidos, a Suprema Corte firmou entendimento de que sua origem está na cláusula do devido processo legal. No Brasil, a doutrina majoritária e o STF adotam esse entendimento. Sobre a matéria, afirma Pereira (2018, p. 361):

O fundamento do princípio da proporcionalidade está na estrutura das normas que consagram os direitos fundamentais. Assim, a noção de proporcionalidade é correlativa ao conceito de princípio, entendido como um comando que deve ser realizado da melhor medida possível, segundo as possibilidades fáticas e jurídicas existentes. As possibilidades fáticas de realização de um princípio são aferidas por meio dos subprincípios da adequação e da necessidade. Já suas possibilidades jurídicas são dadas a partir da ponderação entre os princípios opostos, correspondendo à proporcionalidade em sentido estrito.

A jurisprudência alemã dividiu o princípio da proporcionalidade em três subprincípios: da adequação, da necessidade e da proporcionalidade propriamente dita (sentido estrito). A adequação é a compatibilidade entre o meio empregado e o fim perseguido. Em outras palavras, é eficácia da medida para produzir o resultado visado. Já a necessidade é a utilização do meio menos gravoso para a consecução dos fins visados. Nesse ponto, a razoabilidade se expressa pelo princípio da vedação do excesso. Por sua vez, a proporcionalidade em sentido estrito consiste na ponderação entre o ônus imposto e o benefício trazido, para constatar se a medida é legítima. Esse é o elo entre o princípio da proporcionalidade e a técnica da ponderação.

\section{PROCESSO DE PONDERAÇÃO NA CONSTRUÇÃO CIVIL EM TEMPOS DE COVID-19}

\section{Cumprimento de etapas: preliminar e de mérito}

A COVID-19 ceifou muitas vidas e interrompeu muitos sonhos. Em todo ambiente há risco de contágio, pois o coronavírus se infiltrou no cotidiano das pessoas, sem respeitar limites. Especialmente, o local de trabalho se tornou o ambiente fértil para o contágio. Dentre outros fatores, destacam-se as aglomerações de pessoas, a falta de higienização permanente e a não utilização dos equipamentos de proteção individual adequados. São situações que aumentam o risco de adoecimento pela COVID-19 na maioria dos ambientes de trabalho.

Nos canteiros de obra, essa realidade é preocupante. Os citados fatores se associam a outras violações normativas que elevam, ainda mais, o risco de contágio pela COVID-19. É evidente a falta de estrutura e condições adequadas nas áreas de

Laborare. Ano IV, Número 6, Jan-Jun/2021, pp. 172-193. ISSN 2595-847X. https://revistalaborare.org/ DOI: https://doi.org/10.33637/2595-847x.2021-71 
vivência. Nesse contexto, a Norma Regulamentadora n. 18 (NR-18) estabelece, no item 18.1.1:

\begin{abstract}
Diretrizes de ordem administrativa, de planejamento e de organização, que objetivam a implementação de medidas de controle e sistemas preventivos de segurança nos processos, nas condições e no meio ambiente de trabalho na indústria da construção. Nos limites mínimos estabelecidos no item 18.4.1 da mesma norma, os canteiros de obras devem dispor de: a) instalações sanitárias; b) vestiário; c) alojamento; d) local de refeições; e) cozinha, quando houver preparo de refeições; f) lavanderia; g) área de lazer; h) ambulatório, quando se tratar de frentes de trabalho com 50 (cinquenta) ou mais trabalhadores (NR 18, 2020).
\end{abstract}

Nas áreas de vivência, normalmente não é levado em consideração o princípio da dignidade da pessoa humana. No contexto atual, tornou-se a principal preocupação com o risco de contágio pela COVID-19, na construção civil. A título de exemplo, em meados de maio de 2020, a auditoria fiscal do trabalho em João Pessoa encontrou, em plena pandemia, um canteiro de obra com trezentos empregados em atividade. No entanto, não havia áreas de vivência constituídas em observância às diretrizes da NR-18.

Assim, na etapa preliminar, o auditor fiscal do trabalho observa se o direito fundamental ao exercício da atividade econômica, previsto constitucionalmente, colide com outros direitos fundamentais insculpidos na Carta Maior, destacando-se os seguintes: os valores sociais do trabalho (art. $\left.1^{\circ}, \mathrm{IV}\right)$; a dignidade da pessoa humana (art. $1^{\circ}$, III); a saúde do trabalhador (art. $7^{\circ}$, XXII); o direito à saúde coletiva (art.196) e o direito ao meio ambiente saudável e equilibrado (art. $225, \S 1^{\circ}, \mathrm{V}$ ). Na etapa de mérito, serão observados os seguintes subprincípios:

\title{
Subprincípio da adequação ou idoneidade
}

O passo inicial a ser dado pelo auditor fiscal do trabalho, na etapa de mérito, é identificar a finalidade do embargo como medida restritiva ao direito fundamental à livre iniciativa. Analisa também se o objetivo visado pelo embargo tem respaldo na Constituição Federal e na legislação infraconstitucional. Nessa etapa, deve ser examinado se o embargo atende o subprincípio da adequação. Exige-se que a restrição ao direito fundamental da livre iniciativa seja o meio adequado para atender o fim constitucionalmente estabelecido. No caso em exame, é a redução dos riscos de contágio dos trabalhadores pela COVID-19 no canteiro de obra.

O embargo, nesse contexto, é a medida apta para proteger os trabalhadores do contágio pela COVID-19 e, por extensão, seus familiares e pessoas mais próximas. A

Laborare. Ano IV, Número 6, Jan-Jun/2021, pp. 172-193. ISSN 2595-847X. https://revistalaborare.org/ DOI: https://doi.org/10.33637/2595-847x.2021-71 
medida restritiva deve ser aplicada para evitar aglomerações de trabalhadores quando usarem instalações sanitárias, vestiário, local para refeição e alojamento, exigindo-se as necessárias adequações. Exige-se, além disso, o cumprimento da norma, quando não existem áreas de vivência no canteiro de obra.

Nessas hipóteses, determina-se a paralisação temporária da obra, permitindo o isolamento dos empregados nas suas residências, até a construção ou o dimensionamento das referidas áreas. O objetivo da medida restritiva é garantir a saúde dos trabalhadores e dos seus familiares, bem como o respeito à sua dignidade. O embargo terá elevado grau de eficácia na proteção dos trabalhadores contra a disseminação do coronavírus. Por todos esses motivos, a medida interventiva mostrase apta a atingir o objetivo pretendido.

\section{Subprincípio da necessidade}

Como segundo passo, o auditor fiscal do trabalho deve interpretar e aplicar o subprincípio da necessidade. Observa se não há outro meio menos oneroso do que o embargo que viabilize a proteção dos trabalhadores contra o contágio pela COVID-19, no ambiente do trabalho. Deve observar, especialmente, se existem áreas de vivência no canteiro de obra ou, caso existam, se são adequadas. Nessa situação, o embargo impõe-se como medida necessária, por revelar-se menos onerosa e mais eficaz (RE 433.343-1/SP). O legislador instituiu o embargo como meio eficaz e menos lesivo ao direito fundamental à livre iniciativa, quando há evidência de grave e iminente risco à saúde do trabalhador. Na hipótese analisada, deve prevalecer a vontade do legislador, aplicando-se o princípio da presunção de constitucionalidade das normas regulamentadoras, para proteger a saúde do trabalhador em seu ambiente de trabalho.

\section{Subprincípio da proporcionalidade em sentido estrito}

A aplicação do subprincípio da proporcionalidade em sentido estrito, na construção civil, representa a parte final do processo de solução de conflitos entre direitos constitucionais em rota de colisão. Deve ser efetivado em três fases. Na primeira, cabe ao auditor fiscal do trabalho identificar a intensidade da restrição ao direito fundamental à livre iniciativa, no âmbito da construção civil. Na segunda, foca sua atenção na necessidade de garantia do direito fundamental ao trabalho digno, bem como à saúde do trabalhador e da coletividade, observando também o princípio da proteção ao meio ambiente do trabalho. Na terceira etapa, avalia se a preservação dos direitos fundamentais dos trabalhadores é apta a justificar a restrição ao princípio fundamental à livre iniciativa. Discorrendo sobre a matéria, enfatiza Pereira (2018, p. 382):

Laborare. Ano IV, Número 6, Jan-Jun/2021, pp. 172-193. ISSN 2595-847X. https://revistalaborare.org/ DOI: https://doi.org/10.33637/2595-847x.2021-71 
A realização do subprincípio da proporcionalidade em sentido estrito pressupõe um processo mais amplo de atribuição de pesos, o qual deve envolver, de um lado, a mensuração quantitativa concreta do grau de restrição do direito restringido e de promoção da finalidade buscada e, do outro, a valoração da importância material que os bens jurídicos em jogo ostentam no sistema constitucional. O elemento quantitativo e o material determinam, respectivamente, o peso concreto e o peso abstrato do princípio. Para avaliar a importância da realização de cada princípio envolvido no processo de ponderação, devem ser considerados tanto o peso concreto como o seu peso abstrato.

Para que se possa determinar qual dos direitos fundamentais em disputa prevalecerá, é relevante trazer à tona a seguinte premissa formulada pela Corte Constitucional alemã: "Quanto maior é o grau de afetação ou de não satisfação de um dos princípios, maior deve ser a importância da satisfação do outro". Trata-se do exercício de ponderação. Em suas considerações, a citada autora acrescenta:

A lei de ponderação significa que, para que uma medida restritiva de direitos seja constitucional, deve haver, pelo menos, uma relação de correspondência ou equivalência entre a gravidade da restrição ao direito fundamental e a relevância da implementação do princípio constitucional que fundamenta essa restrição. Isso ocorre porque é viável escalonar a intensidade das intervenções nos direitos fundamentais de forma a qualificálas como leves, médias ou graves, tornando-se possível, assim, estabelecer um resultado racional para a ponderação (PEREIRA, 2018, p. 383).

Nesse trecho de sua obra, Alexy (2002, p. 13-64) faz a seguinte analogia na aplicação da técnica da ponderação:

A determinação de que os produtores de cigarros coloquem nas embalagens avisos quanto ao risco para a saúde que estes representam poderia ser entendida como uma intervenção leve na liberdade de empresa. De forma diversa, a proibição de venda de tabaco em certos lugares ou a interdição do uso de máquinas fornecedoras de cigarros deveria ser qualificada como uma restrição média. Já o impedimento absoluto da venda de produtos derivados do tabaco seria uma interdição grave.

\section{Peso concreto dos direitos fundamentais em choque}


A identificação do peso concreto de um princípio diz respeito à intensidade da restrição ao direito fundamental e ao grau de satisfação do princípio oposto. No caso em análise, a paralisação da obra representa uma restrição de intensidade média ao direito fundamental à livre iniciativa. A suspensão da atividade econômica da construção civil, por meio de embargo, é temporária. Seu objetivo é garantir o isolamento dos empregados durante a construção ou adequação das áreas de vivência. Já o grau de satisfação dos direitos fundamentais ao trabalho digno, à saúde do trabalhador e da coletividade é elevadíssimo.

Tratando-se da garantia da dignidade do trabalhador, a satisfação é dupla. Em primeiro lugar, porque ele é retirado de um ambiente sem instalações sanitárias, sem local para refeição, sem vestiário e sem alojamento adequado. Em segundo, porque a paralisação cria uma perspectiva de trabalho digno com a implantação ou adequação das áreas de vivência.

Sob o ponto de vista da saúde do trabalhador e da comunidade, a satisfação dos direitos fundamentais é imensurável, por envolver a preservação da vida. A permanência do trabalhador no ambiente de trabalho, sem qualquer condição sanitária, aumentará o risco de contágio pela COVID-19. Além disso, a retirada do trabalhador do canteiro de obra previne o início de uma provável cadeia de contaminação, com a transmissão da doença para seus familiares e pessoas próximas. Soma-se a isso a desnecessidade de gastos com o tratamento nos hospitais públicos e com o pagamento de benefícios previdenciários.

\section{Peso abstrato dos direitos fundamentais em choque}

Nessa fase, deve ser analisada a relevância axiológica dos direitos fundamentais em choque, desde que estejam previstos no texto constitucional brasileiro. De um lado, o direito à livre iniciativa; do outro, a dignidade da pessoa humana, o meio ambiente saudável e equilibrado, bem como a saúde do trabalhador e da sociedade. Durante a análise, serão observados os seguintes aspectos:

\section{Peso abstrato do princípio restringido}

$\mathrm{O}$ direito fundamental à livre iniciativa de qualquer atividade econômica lícita tem assento no inciso IV do art. $1^{\circ}$ da Constituição Federal. O citado dispositivo estabelece que os valores sociais do trabalho e da livre iniciativa integram os fundamentos da República Federativa do Brasil. Trata-se de uma norma constitucional de aplicação direta e imediata $\left(\S 1^{\circ}\right.$ do art. $5^{\circ}$ da $\left.\mathrm{CF}\right)$, caracterizando-se como autoaplicável ou de eficácia plena.

Laborare. Ano IV, Número 6, Jan-Jun/2021, pp. 172-193. ISSN 2595-847X. https://revistalaborare.org/ DOI: https://doi.org/10.33637/2595-847x.2021-71 
Vale ressaltar que o legislador constitucional, propositalmente, estabeleceu, no mesmo dispositivo (IV do art. $1^{\circ}$ da CF), o princípio fundamental da livre iniciativa e o princípio fundamental do valor social do trabalho. Significa dizer que, no caso concreto, os direitos de construção, demolição, reparação, manutenção, pintura e limpeza de edifícios em geral e a garantia do direito à saúde e segurança dos trabalhadores devem ser exercidos paralelamente e em harmonia, sempre à luz da Carta Magna. A esse respeito Mousinho (2012, p. 112) enfatiza que o capital está condicionado ao trabalho digno e à dignidade do trabalhador:

Dessume-se, pois, que a ordem econômico-constitucional vigente, no Brasil, conquanto capitalista, está adstrita ao modelo de Estado definido na Constituição, que é o democrático de direito, no qual os princípios da ordem econômica devem ser interpretados com o fito de harmonizá-los com os direitos fundamentais diretamente decorrentes do princípio da dignidade da pessoa humana, eixo axiológico da Carta de 1988. Por isso, o Estado capitalista contemporâneo não se funda na "livre iniciativa", apenas, mas a conjuga com os "valores sociais do trabalho"; não sacraliza a "autonomia privada", mas verifica se essa autonomia pode ser exercida na sua plenitude, desde que não atinja direitos de outrem. Tratase de um Estado que condiciona o exercício da propriedade privada ao cumprimento de sua função social (art. 5, XXII e XXIII; art. 170, II e III, da Constituição Federal).

\section{PESO ABSTRATO DOS DIREITOS FUNDAMENTAIS SATISFEITOS}

O direito fundamental à saúde do trabalhador tem base no inciso XXII do art. $7^{\circ}$ da $\mathrm{CF}$, que consagra o princípio da redução contínua dos riscos inerentes ao trabalho. Nesse sentido, dispõe: "São direitos dos trabalhadores urbanos e rurais, além de outros que visem à melhoria de sua condição social: a redução dos riscos inerentes ao trabalho, por meio de normas de saúde, higiene e segurança".

Discorrendo sobre esses direitos, assinalam Feliciano; Moraes (2019):

Resulta desse princípio constitucional que o direito primacial dos trabalhadores urbanos e rurais não é o de serem "pagos" pelos riscos a que se sujeitam; antes, é o direito à redução dos riscos inerentes ao trabalho. E, como se trata de normaprincípio, esse vetor tanto deve informar a atividade estatal judicante como, antes dela, a própria atividade estatal legiferante e regulamentadora. Daí que, por lógica e essência, será tendencialmente inconstitucional qualquer revisão das normas de saúde, higiene e segurança do trabalho que, em violação literal ao inciso XXII do art. $7^{\circ}$ da Constituição, promova a elevação dos riscos laborais.

Laborare. Ano IV, Número 6, Jan-Jun/2021, pp. 172-193. ISSN 2595-847X. https://revistalaborare.org/ DOI: https://doi.org/10.33637/2595-847x.2021-71 
Por sua vez, o direito fundamental ao meio ambiente saudável e equilibrado tem base constitucional nos art. 225 e 200, VIII, da CF, bem como nas convenções da Organização Internacional do Trabalho (OIT) sobre saúde e segurança, ratificadas pelo Brasil. Na mesma direção, Sarlet e Fensterseifer (2017, p. 83) consideram o direito fundamental ao meio ambiente uma cláusula pétrea, justificando:

Inicialmente cabe destacar que não há qualquer distinção quanto ao regime jurídico ou força jurídica a ser aplicada aos direitos fundamentais presentes no catálogo e àqueles incluídos no rol através da abertura do art. $5^{\circ}, \S 2^{\circ}$, da $\mathrm{CF} / 1988$, tendo, portanto, o direito fundamental ao ambiente aplicação imediata, na linha do que dispõe o $\S 1^{\circ}$ do art. $5^{\circ}$, bem como constituindo-se de norma de eficácia direta e irradiante sob todo o ordenamento jurídico e passando a integrar o rol das cláusulas pétreas (art.60, § 4º IV, da CF/1988). Ao declarar ser a qualidade ambiental essencial a uma vida humana saudável (e também digna), o constituinte consagrou no pacto constitucional sua escolha de incluir na proteção constitucional entre os valores permanentes e fundamentais da república brasileira.

O conjunto de direitos sociais está relacionado no art. $6^{\circ}$ da Constituição Federal, ao estabelecer: "São direitos sociais a educação, a saúde, a alimentação, o trabalho, a moradia, o transporte, o lazer, a segurança, a previdência social, a proteção à maternidade e à infância, a assistência aos desamparados, na forma desta Constituição". No caso específico do direito fundamental à saúde, o art.196 da Carta Magna preceitua: "A saúde é direito de todos e dever do Estado, garantido mediante políticas sociais e econômicas que visem à redução do risco de doença e de outros agravos e ao acesso universal e igualitário às ações e serviços para sua promoção, proteção e recuperação".

Portanto, há elevado grau de fundamentalidade nos princípios consagradores do valor social do trabalho e da proteção ao meio ambiente, bem como do direito à saúde do trabalhador e da coletividade. Eles foram erigidos à categoria de fundamentos da República Federativa do Brasil. Além disso, esses direitos fundamentais possuem uma íntima relação com a dignidade da pessoa humana, conforme esclarece Wolfgang (SARLET, 2009, p. 21-23):

O meio ambiente do trabalho sadio e equilibrado é um direito fundamental, em razão de sua importância e da relação direta com o princípio da dignidade da pessoa humana. Garantir a segurança e a saúde do trabalhador significa respeitar o princípio da dignidade da pessoa humana. Conforme se depreende da Constituição da República, é o

Laborare. Ano IV, Número 6, Jan-Jun/2021, pp. 172-193. ISSN 2595-847X. https://revistalaborare.org/ DOI: https://doi.org/10.33637/2595-847x.2021-71 
princípio vetor de todas as demais normas constitucionais e infraconstitucionais referentes aos direitos humanos, incluindo tratados e convenções internacionais recepcionados pelo sistema normativo brasileiro. Dignidade da pessoa humana é uma qualidade intrínseca de cada indivíduo, sendo reconhecida internacionalmente. Essa prerrogativa o faz merecedor de respeito e consideração por parte do Estado e da comunidade. Envolve um complexo de direitos e deveres fundamentais, oponível contra qualquer ato de cunho degradante e desumano, que possa comprometer ou reduzir, na pessoa humana, as condições existenciais mínimas para uma vida saudável.

Vale ressaltar que o princípio da dignidade deve contemplar a dignidade na relação de trabalho e a dignidade do trabalhador. Na construção civil, para tornar digna a relação de trabalho, o construtor deve colocar à disposição do trabalhador todas as áreas de vivência adequadas ao uso, além de cumprir as demais obrigações trabalhistas. A dignidade do trabalhador não está na relação de trabalho, mas é necessário que seja reconhecida e respeitada pelo empregador. $\mathrm{Na}$ prática, o trabalhador da construção civil, como da maioria das atividades econômicas, é tratado como mercadoria pelo empregador, pois a vida privada e a intimidade do trabalhador se confundem com a existência do empreendimento. O Tribunal Superior do Trabalho (TST) tem decidido, de forma reiterada, no sentido de garantir ao trabalhador a reparação pelo dano existencial devido à jornada excessiva de trabalho, à homofobia, ao assédio moral e a não concessão de férias (TST, 2011, 2013, 2015).

É importante enfatizar que a garantia dos requisitos básicos à saúde e à segurança no ambiente de trabalho é condição indispensável para o exercício dos demais direitos fundamentais inerentes às relações trabalhistas. A doutrina civilista extrai do princípio da dignidade da pessoa humana os denominados direitos da personalidade, reconhecidos a todos os seres humanos e oponíveis aos demais indivíduos e ao Estado. Sob a ótica privatista, mas tendo base constitucional, os direitos da personalidade inerentes à dignidade humana distribuem-se em dois grupos: direito à integridade física e direito à integridade moral, ambos convergindo para o direito à vida. Assim, não há dúvida de que empregados sem proteção ficam, potencialmente, destituídos do direito à integridade física (VIDAL; SOUSA, 2018).

O peso abstrato dos direitos fundamentais deve, também, passar pela análise da teoria clássica de Jellinek, que reconhece a divisão em direitos negativos e positivos. Os primeiros advêm de um processo de abstenção do Estado. Já os direitos positivos exigem do Estado e dos particulares obrigações afirmativas. Têm por objetivo atenuar

Laborare. Ano IV, Número 6, Jan-Jun/2021, pp. 172-193. ISSN 2595-847X. https://revistalaborare.org/ DOI: https://doi.org/10.33637/2595-847x.2021-71 
desigualdades, podendo ser exercidos em sentido amplo (prestação por meio de proteção normativa) e em sentido estrito (prestações materiais).

Em relação ao tema em exame, o direito fundamental positivo, exercido por meio de proteção normativa, está previsto nos seguintes dispositivos da Constituição Federal: art. $1^{\circ}$, IV, que reconhece os valores sociais do trabalho; art. $1^{\circ}$, III, que consagra a dignidade da pessoa humana; art. $7^{\circ}$, XXII, que garante a saúde do trabalhador; art.196, que dispõe sobre a saúde coletiva; art. $225, \S 1^{\circ}, \mathrm{V}$, que prescreve o meio ambiente saudável e equilibrado. Está também previsto nas convenções da OIT sobre saúde e segurança ratificadas pelo Brasil, na CLT e nas normas regulamentadoras n. ${ }^{\circ}$ 03, 18 e 24.

Já o direito fundamental positivo, que se efetiva por meio de prestações materiais, tem por objetivo criar condições para atenuar desigualdades no campo da saúde e segurança do trabalhador. Efetiva-se, no caso em estudo, na obrigação imposta ao construtor de adequar ou criar as áreas de vivência mínimas exigidas pelas normas regulamentadoras, como prevenção ao risco de contaminação pela COVID-19.

\section{Preponderância da satisfação dos direitos fundamentais}

Nessa fase, o auditor fiscal do trabalho deve fazer um exercício de ponderação entre a relevância da restrição ao direito fundamental à livre iniciativa e a necessidade de efetivação dos direitos fundamentais ao meio ambiente saudável e ao trabalho digno, bem como à saúde do trabalhador e da coletividade. Como resultado dessa ponderação, é estabelecida uma relação de precedência de um dos direitos fundamentais em choque. No caso em análise, o peso das razões que servem de fundamento à restrição ao princípio fundamental da livre iniciativa é alto. Já o peso da restrição do referido direito, por meio do embargo, é médio. Nessa linha, pode-se afirmar que o objetivo da medida restritiva, por meio de embargo, está constitucionalmente justificado.

Vale ressaltar que a precedência concedida aos direitos fundamentais ao meio ambiente saudável, à saúde do trabalhador e da sociedade é medida adequada. Nesse caso, determina-se a paralisação temporária da obra, até o cumprimento das normas regulamentadoras relativas às áreas de vivência e das regras de prevenção ao contágio pela COVID-19. Como se observa, a restrição não afeta o conteúdo do núcleo essencial do direito fundamental, que corresponde, no caso concreto, ao direito de voltar a exercer a atividade econômica, após o cumprimento das normas regulamentadoras. Nesse sentido, esclarece Pereira (2018, p. 385): "Fala-se em relação de precedência condicionada porque a prevalência do princípio que é aplicada na solução não é válida para todos os casos, mas apenas nas condições presentes na situação concreta".

Laborare. Ano IV, Número 6, Jan-Jun/2021, pp. 172-193. ISSN 2595-847X. https://revistalaborare.org/ DOI: https://doi.org/10.33637/2595-847x.2021-71 
O embargo se apresenta, nessa seara, entre a dupla dimensão do princípio da proporcionalidade: a rejeição da proteção insuficiente, de um lado, e a proibição do excesso da intervenção estatal, do outro. No caso sob exame, trata-se de canteiro de obra que não possui áreas de vivência adequadas e, portanto, não cumpre as regras específicas de enfrentamento à COVID-19. Por tal motivo, revela-se como um espaço com proteção insuficiente à saúde e à segurança do trabalhador, bem como ao meio ambiente do trabalho. Por outro lado, a paralisação temporária da obra, por meio de embargo, tem a finalidade de corrigir a proteção insuficiente, sem violar o núcleo essencial da atividade econômica da construção civil e, por conseguinte, sem caracterizar excesso na atuação do auditor fiscal do trabalho.

\section{APLICAÇÃO DA NR-3 À LUZ DO PRINCÍPIO DA PROPORCIONALIDADE EM TEMPOS DE COVID-19}

O grave e iminente risco à saúde do trabalhador e os requisitos técnicos objetivos do embargo estabelecidos na NR-3 devem ser interpretados sob a ótica da COVID-19. Significa dizer que o princípio da proporcionalidade passou a ser aplicado para prevenir o risco de contaminação. Dessa forma, a decisão do auditor fiscal do trabalho de paralisar a construção civil justifica-se diante do risco causado pelo coronavírus à saúde do trabalhador. Para dirimir qualquer dúvida, transcrevem-se as orientações emanadas da Norma Regulamentadora $\mathrm{n}^{\circ}{ }^{\mathrm{j}}$ :

A NR-3 estabelece parâmetros claros para avaliar a 'iminência' e "gravidade' do risco de uma condição ou situação de trabalho, sendo o risco expresso em termos de uma combinação das consequências (tabela 3.1 da NR-3) de um evento e da probabilidade (tabela 3.2 da NR-3) da sua ocorrência. A consequência é determinada em função da gra lvidade do evento ocorrido ou como resultado esperado deste evento, enquanto que a probabilidade, em função das medidas de prevenção existentes, sua eficácia e manutenção ao longo do tempo. A caracterização ou não de grave e iminente risco (GIR) em uma condição ou situação de trabalho deve ser feita em 3 (três) etapas. Na primeira etapa, o AFT deve determinar o 'risco atual' quando da constatação de uma situação de risco ao trabalhador no momento da inspeção. Neste momento, o AFT deve inicialmente classificar a consequência do acidente/doença ocupacional caso venha a ocorrer. Ato contínuo, deve classificar a probabilidade da ocorrência do acidente/doença ocupacional em função das medidas de prevenção existentes. Na segunda etapa, o AFT deve novamente classificar a consequência e a probabilidade de ocorrência do acidente/doença ocupacional, a partir das medidas legais de prevenção previstas na legislação brasileira de segurança e saúde no trabalho, o chamado 'risco de referência', que já deveriam ter sido adotadas pelo empregador. Na terceira etapa, o AFT deve determinar o 'excesso de risco', em função do 'risco atual' (classificado

Laborare. Ano IV, Número 6, Jan-Jun/2021, pp. 172-193. ISSN 2595-847X. https://revistalaborare.org/ DOI: https://doi.org/10.33637/2595-847x.2021-71 
no momento da inspeção - etapa 1) e do 'risco de referência' (objetivo, caso a organização adote as medidas de prevenção necessárias - etapa 2) (BRASIL, 2019).

Conforme já enfatizado, a falta de áreas de vivência e o não cumprimento das regras de enfrentamento à COVID-19 trazem como consequência a contaminação de trabalhadores, podendo causar-lhes a morte. É provável a probabilidade de tal evento ocorrer, pois, as medidas de prevenção são inexistentes. Para o risco objetivo, a consequência, também, pode ser a morte de trabalhadores, com a remota probabilidade de sua ocorrência, se as medidas legais de prevenção fossem adotadas pelo empregador. Assim, o excesso de risco é substancial, em razão da diferença entre o risco atual e o risco objetivo, respaldando a decisão proporcional do auditor fiscal do trabalho na paralisação da obra. Acrescenta-se que, mesmo com todas as medidas de prevenção implantadas nas áreas de vivência e o cumprimento das regras específicas de combate à COVID-19, a probabilidade de contaminação não está descartada.

Vale relevar que, antes da pandemia, o índice de acidente de trabalho, na construção civil, já era altíssimo. Em 2019, somente a atividade de construção de edifícios ocupou o oitavo lugar dentre todas as atividades econômicas, com 7.593 acidentes, conforme informações da Subsecretaria de Inspeção do Trabalho (SIT) (SIT, 2019). Como resultado da carência das áreas de vivência em tempos de coronavírus, certamente, os números serão ainda mais alarmantes, exigindo-se cuidados redobrados.

O embargo e a interdição são medidas administrativas e cautelares cujo objetivo é assegurar o ambiente do trabalho sadio e equilibrado. No entanto, observa-se um flagrante descumprimento das normas de saúde e segurança por parte das empresas da construção civil. Esse cenário justifica o aumento do número de lavraturas dessas medidas assecuratórias da saúde dos trabalhadores e dos seus familiares.

Conforme dados da SIT, em 2015, foram lavrados 6.450 embargos e interdições, havendo uma redução nos anos seguintes: 5.037, em 2016; 4.821, em 2017; 4.650, em 2018 e 4.436, em 2019. Certamente, em 2020, a queda do número de embargos e interdições será ainda maior, levando-se em consideração a inatividade de muitos auditores fiscais do trabalho e a entrada em vigor da nova NR-3. Em razão disso, o presente trabalho defende a inversão dessa tendência de queda, com a lavratura de mais embargos e interdições. Essas medidas resultarão na melhor prevenção de acidentes e doenças ocupacionais, especialmente, no combate à COVID-19. Feliciano; Moraes (2019) apresentam um quadro desalentador, mesmo antes da pandemia, com impactos sociais e econômicos extremamente negativos:

Laborare. Ano IV, Número 6, Jan-Jun/2021, pp. 172-193. ISSN 2595-847X. https://revistalaborare.org/ DOI: https://doi.org/10.33637/2595-847x.2021-71 
O Brasil figura no cenário internacional como o $4^{\circ}$ país do mundo em números de acidentes de trabalho. Segundo dados do Observatório Digital de Saúde e Segurança do Trabalho do Ministério Público do Trabalho, entre 2012 e 2018, ocorreram no país cerca de 4.738 .886 acidentes de trabalhos notificados - sendo 17.315 com óbito -, o que corresponde à média de um acidente de trabalho a cada 49 segundos. Isto significou, entre 2012 e 2018, 370.174.000 dias de afastamento previdenciário, impondo à Previdência Social custos na ordem de R $\$ 83$ bilhões de reais em benefícios acidentários. Segundo a Organização Internacional do Trabalho (OIT), os acidentes e doenças de trabalho resultam na perda anual de 4\% do produto interno bruto, percentual que, no Brasil, corresponde a R 264 bilhões, considerando o PIB de 2017.

\section{CONSIDERAÇÕES FINAIS}

No Brasil, conforme dados divulgados no fim de janeiro de 2021, já morreram mais de 224 mil pessoas por causa da COVID-19. Muitas vítimas eram trabalhadores e trabalhadoras dos diversos setores econômicos. A construção civil vem sendo um dos mais afetados pela doença. A falta de áreas de vivência nos canteiros de obra tem agravado, cada vez mais, um setor caracterizado por muitos acidentes do trabalho. Os trabalhadores clamam por mudanças que possam dar-lhes maior proteção em uma das atividades econômicas que mais gera emprego no país.

Em pleno século XXI, apesar do catálogo de direitos fundamentais previstos na Carta Magna, conhecida como Constituição Cidadã, ainda há trabalhadores que se alimentam sentados em tijolos; que fazem suas necessidades fisiológicas em local sem as instalações sanitárias; que bebem a mesma água que é colocada dentro da betoneira e que dormem em espaço confinado, com camas improvisadas. Trata-se de um ambiente de trabalho totalmente suscetível à propagação do coronavírus. Essa é a realidade de grande parte dos canteiros de obra.

Esse problema grave e complexo desafia soluções urgentes. Algumas medidas se impõem como inadiáveis: participação da sociedade por meio de denúncias; presença mais efetiva do Estado por meio de inspeção do trabalho, tanto orientadora como punitiva, quando for o caso; mudança nos procedimentos do empreendedor da construção civil, melhorando a gestão em saúde e segurança. Estes são fatores imprescindíveis para a observância, por parte dos próprios construtores, dos princípios fundamentais da dignidade da pessoa humana e do valor social do trabalho.

Ante a inércia dos empregadores da construção civil em seu dever de resguardar tais direitos, cabe ao auditor fiscal do trabalho aplicar as medidas adequadas, por meio do

Laborare. Ano IV, Número 6, Jan-Jun/2021, pp. 172-193. ISSN 2595-847X. https://revistalaborare.org/ DOI: https://doi.org/10.33637/2595-847x.2021-71 
embargo. Deve aplicar esse remédio amargo, especialmente, quando não há áreas de vivência no canteiro de obra ou quando elas são inadequadas. Os principais objetivos da medida são: harmonizar os interesses econômicos com os direitos fundamentais dos trabalhadores; reduzir a precarização do trabalho; preservar o núcleo essencial da atividade econômica da construção civil e prevenir contra acidentes e doenças ocupacionais.

\section{REFERÊNCIAS BIBLIOGRÁFICAS}

ALEXY, Robert Alexy. Teoría de los derechos fundamentales. Madri: Centro de Estudios Constitucionales, 1997, p.86.

. Epilogo a la teoria de los derechos fundamentales. Revista Española de Derecho Constitucional. Madri: n. ${ }^{\circ}$ 66, 2002, p. 13-64.

ÁVILA, Humberto Bergmann. A distinção entre princípios e regras e a redefinição do dever de proporcionalidade. Revista Diálogo Jurídico, v. 1, n. 4, 2001. Disponível em: http://www.direitopublico.com.br. Acesso em: 06 jul. 2020.

BARROSO, Luís Roberto. Curso de direito constitucional contemporâneo: os conceitos fundamentais e a construção de um novo modelo. 8 . ed. São Paulo: Saraiva, 2019, p. 509.

. Curso de direito constitucional contemporâneo: os conceitos fundamentais e a construção de um novo modelo. 7. ed. São Paulo: Saraiva, 2018, p. $243 / 246$.

BRASIL. Ministério da Economia. Subsecretaria de Inspeção do Trabalho. Norma $\begin{array}{lllllll}\text { Regulamentadora } & \mathbf{n} .^{0} & \mathbf{3} & \text { (NR-3). } & \text { 2019. } & \text { Disponível } & \text { em: }\end{array}$ https://sit.trabalho.gov.br/portal/index.php/ctpp-nrs/nr-3?view=default. Acesso em: 10 nov. 2020.

. Ministério da Economia. Inspeção do trabalho. Norma Regulamentadora n. ${ }^{0} 18$ - Condições e meio ambiente de trabalho na indústria da construção. 2020. Disponível em: https://sit.trabalho.gov.br/portal/images/SST/SST_normas_regulamen tadoras/NR-18.pdf. Acesso em: 10 nov. 2019.

. Ministério da Economia. Subsecretaria de Inspeção do Trabalho. Atividades econômicas. Índice de acidente de trabalho. 2019. Disponível em: https://sit.trabalho.gov.br. Acesso em: 25 jan. 2021.

DELGADO, Maurício Godinho. Curso de direito do trabalho. 13. ed. São Paulo: LTr, 2014, p. 150.

FELICIANO, Guilherme Guimarães; MORAES, Paulo Douglas de Almeida. Normas de saúde e segurança do trabalho na era Bolsonaro: discutindo a profundidade de

Laborare. Ano IV, Número 6, Jan-Jun/2021, pp. 172-193. ISSN 2595-847X. https://revistalaborare.org/ DOl: https://doi.org/10.33637/2595-847x.2021-71 
um fosso. 2019. Associação Nacional dos Procuradores do Trabalho - ANPT. Disponível em: http://www.anpt.org.br/nossos-autores/artigos/3543-normas-de-saudee-seguranca-do-trabalho-na-era-bolsonaro-discutindo-a-profundidade-de-um-fosso.

Acesso em: 10 nov. 2019.

MOUSINHO, Ileana Neiva. Estudos aprofundados MPT. Salvador: Editora Juspodivm, 2012, p. 112.

PEREIRA, Jane Reis Gonçalves. Interpretação constitucional e direitos fundamentais. 2. ed. São Paulo: Saraiva, 2018, p. 385.

SARLET, Ingo Wolfgang. Dimensões da dignidade: ensaios de filosofia do direito e direito constitucional. 2. ed. Porto Alegre: Livraria do Advogado Editora, 2009, p. 21-23).

SARLET, Ingo Wolfgang; FENSTERSEIFER, Tiago. Direito constitucional ambiental. 5. ed. São Paulo: Revista dos Tribunais, 2017, p. 83.

TRIBUNAL SUPERIOR DO TRABALHO. Disponível em http://aplicacao4.tst.jus.br/consultaProcessual/consultaTstNumUnica.do;jsessionid=5 D104B68D408C9791BA6665EAC03172F.vm652? conscsjt $=$ \&numeroTst $=727 \&$ digitoTst $=76 \&$ anoTst $=2011$ \&orgaoTst $=5 \&$ tribunalTst $=$ $24 \&$ varaTst $=0002 \&$ consulta $=$ Consultar. Acesso em: 25 jan. 2021.

.Disponível

em

http://aplicacao4.tst.jus.br/consultaProcessual/consultaTstNumUnica.do?

consulta $=$ Consultar $\&$ conscsjt $=$ \&numeroTst $=3030 \&$ digitoTst $=13 \&$ anoTst $=2013 \&$ orga oTst $=5 \&$ tribunalTst $=15 \&$ varaTst=0077\&submit=Consultar. Acesso em: 25 jan. 2021.

. Disponível em: https://www.tst.jus.br/web/guest/-/encarregadoconsegue-aumentar-valor-de-indenização-após-situação-de-homofobia. Acesso em: 25 jan. 2021.

VIDAL, Rui Silva; SOUSA, Ulisses Freitas. Assistência em segurança e saúde no trabalho por um SESMT: direito do trabalhador e obrigatoriedade para todas as empresas. Revista da Escola Nacional da Inspeção do Trabalho, ano 2, 2018. Disponível em: https://enit.trabalho.gov.br/revista/index.php?journal=Revista Enit\&page $=$ article\&op $=$ view\&path\%5B\%5D=47. Acesso em: 10 nov. 2020.

Recebido: 08/12/2020

Revisado: 01/02/2021

Aprovado: 04/02/2021

Laborare. Ano IV, Número 6, Jan-Jun/2021, pp. 172-193. ISSN 2595-847X. https://revistalaborare.org/ DOI: https://doi.org/10.33637/2595-847x.2021-71 